\title{
Use of the Harmonic Direction Finder to study the terrestrial habitats of the European tree frog (Hyla arborea)
}

\author{
Jérôme Pellet ${ }^{1}$, Luca Rechsteiner ${ }^{1}$, Anja K. Skrivervik ${ }^{2}$, Jean-François Zürcher ${ }^{2}$, Nicolas Perrin ${ }^{1}$
}

Although most amphibians spend a substantial part of their life in terrestrial habitats (Dodd and Cade, 1998; Semlitsch, 1998; Semlitsch and Jensen, 2001), herpetological research has mostly focused on breeding aggregations in wetlands (Duellman and Trueb, 1986; Alford and Richards, 1999). Consequently, very little data are available on the terrestrial ecology of most species (Gibbons, 2003). This lack of information hinders the development and application of efficient amphibian conservation policies. Without proper conservation of terrestrial habitats, even the most common amphibian species are susceptible to decline (Johnson, 2003). The need for extensive and scientific knowledge on amphibians' terrestrial habitats is extremely important in a context of evidencebased conservation (Pullin et al., 2004; Sutherland et al., 2004). Data on the use of terrestrial habitat by amphibians is unfortunately very hard to obtain without using labour- and costintensive methods such as telemetry (Heyer et al., 1994). Since the 1960s, authors have tried to address this issue by equipping amphibians with different tracking systems, which facilitate the location of cryptic animals. Thread bobbin trailing devices (Dole, 1965), $\mathrm{Co}^{60}$ radioactive tags (Karlstrom, 1957; Barbour et al., 1969; Ashton, 1975), fluorescent pigments (Eggert, 2002), and radio emitter (Sinsch, 1989;

1 - Laboratory for Conservation Biology, Department of Ecology and Evolution, University of Lausanne, CH-1015 Dorigny, Switzerland e-mail: jerome.pellet@unil.ch

2 - Laboratoire d'Electromagnétisme et d'Acoustique, EPFL/STI/ITOP/LEMA, Bâtiment ELB, Station 11, CH-1015 Lausanne, Switzerland
Vos, 1999; Eggert, 2002; Bulger et al., 2003; Schabetsberger et al., 2004) have been applied to a wide range of species. These methods have proven efficient in answering many ecological and behavioural questions but are limited by either the weight of the attached equipment $(10 \%$ of individual's body mass, Richards et al., 1994) or its longevity (Dole, 1965; Kenward, 1987; White and Garrot, 1990). More recently, experiments on insects (Lovei et al., 1997; Capaldi et al., 2000; Riley et al., 1996), reptiles (Engelstoft et al., 1998), frogs (Langkilde and Richards, 2002) and toads (Leskovar and Sinsch, in press) have used harmonic direction finders (HDF). Since this method is based on microwaves reflection and the attached transponder does not require batteries, the latter has a potentially endless life. Moreover, these devices are relatively lightweight making them potentially suitable for many small species, including amphibians. Here we present details of the development of a miniature harmonic transponder and describe its effectiveness in studying the terrestrial movements of the European tree frog (Hyla arborea).

The HDF is a portable scanning device originally developed for the rescue of avalanche victims which includes both an emitter and receiver (sold for $\$ 6,660$ by RECCO AB, Box 4028, SE-181 04 Lidingö, Sweden). The HDF sends a directional and polarized microwave at a precise frequency $(870 \mathrm{MHz})$, which is doubled $(1740 \mathrm{MHz})$ on hitting a reflector (or harmonic transponder). The reflected microwave is detected by the receiver which translates it into an acoustic signal. The user evaluates the amplitude of the reflected microwave beam to determine directionality. The transponder consists of a schottky diode (model R2 RECCO $\mathrm{AB}$ ) soldered between a base plate and a perpendicular wire antenna, the whole system creating an electrical dipole costing $\sim \$ 2$. The wire antenna is mounted vertically to obtain optimum detection range and is wound at its base to form a small helix which acts as a small spring, giving more flexibility to the antenna. Beryllium bronze $(\mathrm{BzBe})$ is used for 


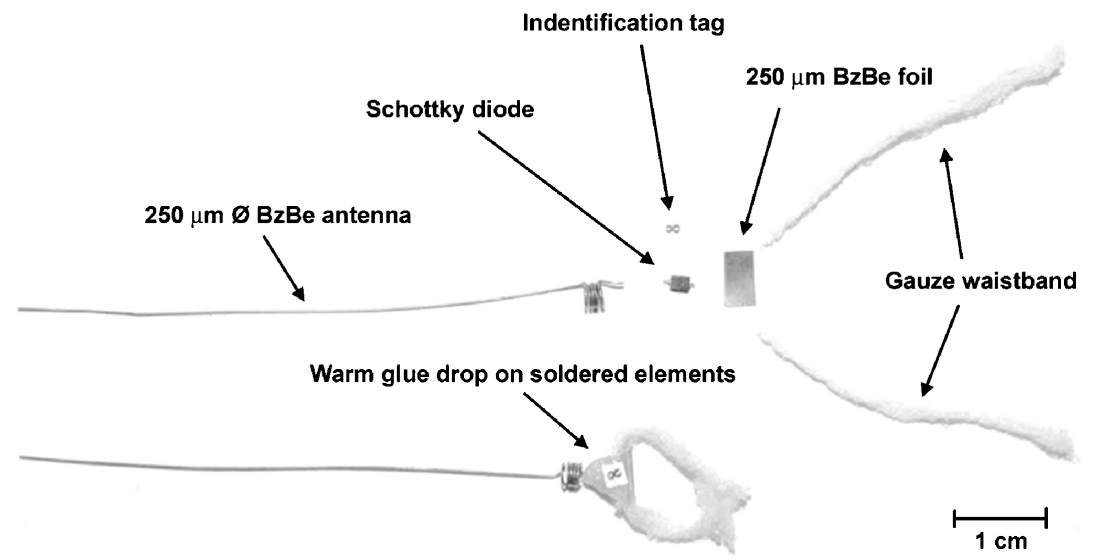

Figure 1. The elements of a waistband-fixed anuran harmonic transponder.

both the base plate and for the radiating wire, because of its high conductivity and mechanical elasticity. This latter property guarantees that the antenna recovers its original shape after being bent during animal's movements through dense vegetation. The length of the antenna and the small size of tree frogs ( $\sim 4 \mathrm{~cm}$ snout-to-vent, and weight $\sim 6 \mathrm{~g}$ ) prohibit implantation of transponders. Cyanoacrylate glues cause skin damage to Ranidae and Hylidae (U. Sinsch, pers. com.). Thus, we used waistbands to attach transponders, which have proven useful for similar studies (Fukuyama et al., 1988; Hodgkison and Hero, 2001). Waistbands are made of gauze from which the cotton linings are removed. The advantage of this material is its elasticity and the fact that it degrades over a few weeks freeing of their equipment the animals not recaptured after some time.

We tested two aspects of field operation: detection range vs. antenna length and waistband retention time. We first ran systematic trials in which we measured transponder detection range vs. wire antenna length. Second, waistband retention time was tested in terrariums after field experiments started, because we observed an increasing number of detached waistbands in the field. To evaluate the efficiency of the waistband attachment method, 18 tree frogs were captured and kept in a terrarium in which vegetation cover mimicks the field in which they had been captured. Frogs were marked with transponders and waistbands and were checked daily for 3 weeks to document the rate of waistband loss.

To study capabilities of HDF use in the field we captured and monitored movements of frogs during the breeding season and during post-breeding migration. Our study took place in 2004 in one of Switzerland's federally protected amphibian spawning ponds. Located east of the village of Lavigny $\left(46^{\circ} 30^{\prime} \mathrm{N} ; 6^{\circ} 25^{\prime} \mathrm{E}\right.$; see Pellet and Neet, 2001) this breeding pond is a natural meadow depression where ground water emerges temporally from winter to early summer. The surrounding landscape is agricultural, mostly with fields of wheat and corn. Some patches of natural meadow and hedgerow are present in low density, along with two riparian forests. Frogs were captured at dusk on the shore of the pond. Because of the cryptic behaviour of females during the breeding season, only males were marked with transponders. Frogs were manipulated and released at their capture locations after 5 minutes. Date, time and GPS location of the capture/release point were recorded on a Trimble GeoExplorer GPS system with a precision of $\sim 1 \mathrm{~m}$. During the rest of the breeding season (midApril to the end of May in western Switzerland) the pond shores and the surrounding landscape were systematically scanned for frogs concealed in the vegetation three times a week during at least 4 hours of daylight. Once a signal was detected, and given the directional signal of the HDF, it was possible to locate transponders by regularly reducing the transmitted power and homing on the target in a centripetal fashion until the animal was discovered and identified with the number tag glued on the transponder. To study postbreeding migration, 15 frogs were detained until 4 weeks after the end of the breeding season (last caller heard) and then one marked frog was released each night on the shore of the pond. We surveyed the movements of the released frogs every 5 minutes from dusk to dawn. At dawn, the observed path and last location of the animal were recorded.

The harmonic transponder and waistband that we constructed (fig. 1) weighed $\sim 0.11 \mathrm{~g}$ and represented $\sim 1.8 \%$ of an average tree frog's body mass $(6 \mathrm{~g})$. Detection ranges increased according to antenna length. When placed on the ground, detection range reached $10 \mathrm{~m}$ with a $3 \mathrm{~cm}$ antenna and increased linearly up to $30 \mathrm{~m}$ with a $10 \mathrm{~cm}$ antenna. Detection range was generally tripled when the transponder was placed at a $0.8 \mathrm{~m}$ height. We decided to opt for a $5.2 \mathrm{~cm}$ antenna, an empirical optimum between equipment dimension and tree frog size and weight. With this configuration, detection range was $12 \mathrm{~m}$ when the transponder was on the ground and $34 \mathrm{~m}$ when the transponder was $0.8 \mathrm{~m}$ high, which is concordant with the results 


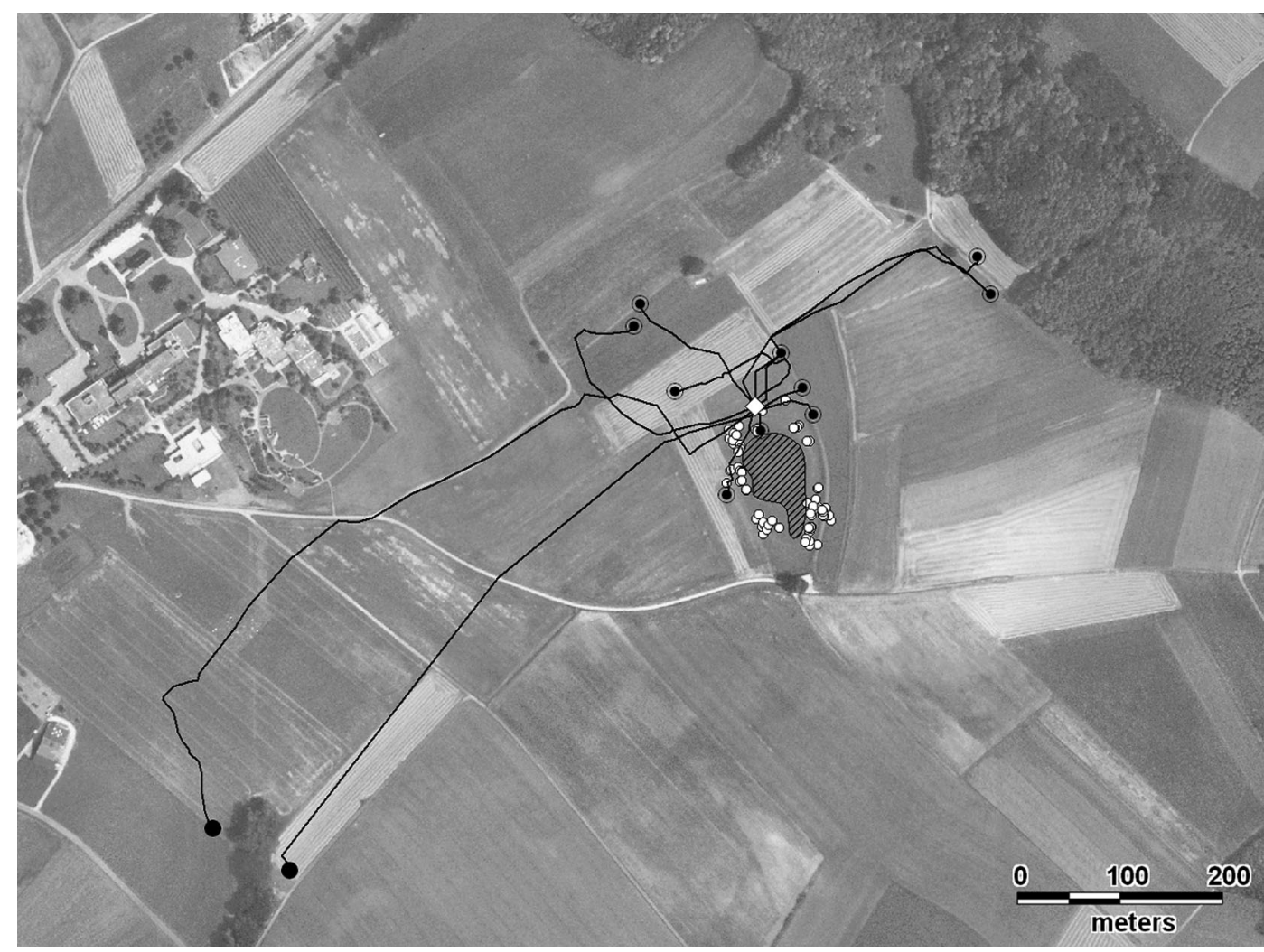

Figure 2. Diurnal locations of breeding tree frogs (small white dots) around the pond (hatched area). Path taken by animal during post-breeding dispersal to summer habitats (white rhombus indicate release point, small black circles are post-breeding locations of frogs lost during migrations, large black circles are locations of frogs on summer ranges).

obtained by Leskovar and Sinsch (in press) with similar equipment. Waistband retention time as observed in the terrarium proved sufficient to track frogs for several days at the most (mean retention time $\pm \mathrm{SD}=7.6 \pm 3.6$ days, range: 1-14 days). At the end of the two weeks trial, only two out of 18 frogs still had a functional waistband. The loss of transponders was a result of apparition of swollen legs and subsequent removal of waistbands ( $n=12$ ), self-removed waistbands $(n=2)$, and turned-over waistbands $(n=2)$. This loss rate is somewhat better than what Leskovar and Sinsch (in press) achieved with cyanoacrylate glues on juveniles of Bufo calamita and B. viridis.

During the breeding period, 29 frogs were marked, of which 26 were recaptured at least once in the following 6 weeks (mean recapture occasions $\pm \mathrm{SD}=2.5 \pm 1.4$, range: $1-7$ re- captures). Four animals were found dead. We thus gathered 79 locations of daytime localities. Most of the recaptured animals had moved less than $40 \mathrm{~m}$ from the release point. In general, tree frogs males did not move far from their spawning site during the breeding season. Fog (1993) compiled data on observed breeding tree frogs less than $22 \mathrm{~m}$ from the pond in nearly 20 incidental daytime observations. Our results from systematic monitoring confirm this range (we found $90 \%$ of our marked frogs within this area) and also indicate that very few animals move than $30 \mathrm{~m}$ away from the pond at this time of the year.

During the first night following their release, the 15 frogs that we marked to study post-breeding migration moved between 18 and $440 \mathrm{~m}$. Ten frogs were lost by dawn of the following day. Of the 5 frogs remaining, 3 were 
found up to 48 hours after they were released, either in natural meadows $(n=2)$ or corn crops $(n=1)$, but never at more than $50 \mathrm{~m}$ from their release points. The last two frogs moved 860 and $660 \mathrm{~m}$ in less than 14 and 40 hours, respectively. Movements were southwest to the vicinity of a riparian woodland where frogs stayed for more than 3 days and were thus considered to have reached their post-breeding habitat (fig. 2). Because our sample size of marked male frogs that arrived at post-breeding habitats was low $(n=2)$, we cannot generalize the terrestrial habitat needs of the European tree frog. Both marked frogs moved to the same riparian woodland, but this could have been due to chance. Nevertheless, our observations of migrating frogs in spring corroborate these results. We observed more than 20 frogs in 2001-2004 migrating to the ponds across the access road exactly where they would be expected had they come in a straight line from the same woodland (Pellet et al., unpubl. data). Tree frogs also have been heard calling from the canopy of ash trees (Fraxinus excelsior) (Pellet et al., unpubl. data), which is consistent with observations of Schmidt et al. (2003), who discovered tree frogs $30 \mathrm{~m}$ up in the tree canopy. These observations are also consistent with Stumpel (1993) who indicates high air humidity, high intensity of sunlight and complex vegetation structure as determinants of tree frog terrestrial habitats. Although females have also been incidentally observed in this riparian wood, there are no indications so far about sex differences in use of these terrestrial habitats (Stumpel, 1993).

We believe it is important that every potential mean to help identify amphibian terrestrial habitat be evaluated. Because telemetric studies are time-consuming, but can provide unbiased and quality movement information, they should be justified only after assessing the effort-knowledge ratio. In this context, the HDF technology and transponders attachment method for anurans needs to be improved in order to achieve larger detection range and longer equipment retention time. Even though limited in lifespan, we believe that small-sized (less than $0.3 \mathrm{~g}$ ) radio-emitters still constitute our best tool to uncover terrestrial habitats of small anurans, given a reliable attachment method. Only when such tracking tools are available will we be able to identify the terrestrial habitats of cryptic and vagile species such as the European tree frog. The development of efficient and evidence-based amphibian conservation strategies depends on it.

Acknowledgements. This work was funded by the Centre de Conservation de la Faune et de la Nature du canton de Vaud, the MAVA Foundation and the De Giacomi Foundation. Authorization \#1661 for the manipulation of wild animals was granted by the state veterinarian. Thanks to U. Sinsch for helpful discussions on the topic of HDF.

\section{Literature cited}

Alford, R.A., Richards, S.J. (1999): Global amphibian declines: a problem in applied ecology. Annu. Rev. Ecol. Syst. 30: 133-165.

Ashton, R.E. (1975): A study of movement, home range, and winter behaviour of Desmognathus fuscus (Rafinesque). J. Herpet. 9: 85-91.

Barbour, R.W., Hardin, J.W., Schafer, J.P., Harvey, M.J. (1969): Home range, movements, and activity of the dusky salamander, Desmognathus fuscus. Copeia 2: 293297.

Bulger, J.B., Scott, N.J., Seymour, R.B. (2003): Terrestrial activity and conservation of adult California red-legged frogs Rana aurora draytonii in coastal forests and grasslands. Biol. Conserv. 110: 85-95.

Capaldi, E.A., Smith, A.D., Osborne, J.L., Fahrbach, S.E., Reynolds, D.R., Edwards, A.S., Martin, A., Robinson, G.E., Poppy, G.M., Riley, J.R. (2000): Ontogeny of orientation flight in the honeybee revealed by harmonic radar. Nature 403: 537-540.

Dodd, C.K., Cade, B.S. (1998): Movement patterns and the conservation of amphibians breeding in small, temporary wetlands. Conserv. Biol. 12: 331-339.

Dole, J.W. (1965): Summer movements of adult leopard frogs, Rana pipiens Schreber, in northern Michigan. Ecology 46: 236-255.

Duellman, W.E., Trueb, L. (1986): Biology of amphibians. Baltimore, John Hopkins University Press.

Eggert, C. (2002): Use of fluorescent pigments and implantable transmitters to track a fossorial toad (Pelobates fuscus). Herpetol. J. 12: 69-74.

Engelstoft, C., Ovasaka, K., Honkanen, N. (1999): The harmonic direction finder: a new method for tracking movements of small snakes. Herpetol. Rev. 30: 84-87. 
Fog, K. (1993): Migration in the tree frog Hyla arborea. In: Ecology and Conservation of the European tree frog, p. 55-64. Stumpel, A.H.P., Tester, U., Eds, Wageningen, Netherlands, Institute for Forestry and Nature Research.

Fukuyama, K., Kusano, T., Nakane, M. (1988): A radio tracking study of the behavior of females of the frog Buergeria buergeri (Rhacophoridae, Amphibia) in a breeding stream in Japan. Jap. J. Herp. 12: 102-107.

Gibbons, J.W. (2003): Terrestrial habitat: a vital component for herpetofauna of isolated wetlands. Wetlands 23: 630635.

Heyer, W.R., Donnelly, M.A., McDiarmid, R.W., Hayek, L.C., Foster, M.S. (Eds) (1994): Measuring and Monitoring Biological Diversity: Standard Methods for Amphibians. Washington, Smithsonian Institution Press.

Hodgkison, S., Hero, J.-M. (2001): Daily behaviour and microhabitat use of the waterfall Frog, Litoria nannotis in Tully Gorge, Eastern Australia. J. Herpetol. 35: 116120.

Johnson, S.A. (2003): Orientation and migration distances of a pond-breeding salamander (Notophthalmus perstriatus, Salamandridae). Alytes 21: 3-22.

Karlstrom, E.L. (1957): The use of $\mathrm{Co}^{60}$ as tags for recovering amphibians in the field. Ecology 38: 187-195.

Kenward, R.E. (1987): Wildlife radio-tagging. London, Academic Press.

Langkilde, T., Alford, R.A. (2002): The tail wags the frog: attached harmonic radar transponders affect behavior in Litoria lesueuri. J. Herpetol. 36: 711-715.

Leskovar, C., Sinsch, U. (in press): Harmonic direction finding: a novel tool to monitor the dispersal of smallsized anurans. Herpetol. J.

Lovei, G.L., Stringer, J.A.N., Devine, C.D., Cartellieri, M. (1997): Harmonic radar - a method using inexpensive tags to study invertebrate movement on land. New Zeal. J. Ecol. 21: 187-193.

Pullin, A.S., Knight, T.M., Stone, D.A., Charman, K. (2004): Do conservation managers use scientific evidence to support their decision-making? Biol. Conserv. 119: $245-252$.

Richards, S.J., Sinsch, U., Alford, R.A. (1994): Radio Tracking. In: Measuring and monitoring biological diversity: Standard Methods for Amphibians, p. 155-157.
Heyer, W.R., Donnelly, M.A., McDiarmid, R.W., Hayek, L.C., Foster, M.S., Eds, Washington, Smithsonian Institution Press.

Riley, J.R., Smith, A.D., Reynolds, D.R., Edwards, A.S., Osborne, J.L., Williams, I.H., Carreck, N.L., Poppy, G.M. (1996): Tracking bees with harmonic radar. Nature 379: $29-30$.

Schabetsberger, R., Jehle, R., Maletzky, A., Pesta, J., Sztatcsny, M. (2004): Delineation of terrestrial reserves for amphibians: post-breeding migrations of Italian crested newts (Triturus c. carnifex) at high altitude. Biol. Conserv. 117: 95-104.

Schmidt, C., Unterseher, M., Grosse, W.R. (2003): Hoch hinaus - Sitzwarten beim Laubfrosch (Hyla arborea) in Baumkronen des Leipziger Auwalds. Elaphe 11: 43-45.

Semlitsch, R.D. (1998): Biological delineation of terrestrial buffer zones for pond-breeding salamanders. Conserv. Biol. 12: 1113-1119.

Semlitsch, R.D., Jensen, J.B. (2001): Core habitat, not buffer zone. National Wetland Newsletter 23: 5-11.

Sinsch, U. (1989): Migratory behaviour of the common toad (Bufo bufo) and the natterjack toad (Bufo calamita). In: Amphibians and Roads, p. 113-125. Langton, T.E.S., Ed., London, ACO Polymer Products Ltd.

Stumpel, A.H.P. (1993): The terrestrial habitat of Hyla arborea. In: Ecology and Conservation of the European tree frog, p. 47-54. Stumpel, A.H.P., Tester, U., Eds, Wageningen, Netherlands, Institute for Forestry and Nature Research.

Sutherland, W.J., Pullin, A.S., Dolman, P.M., Knight, T.M. (2004): The need for evidence-based conservation. Trends Ecol. Evol. 19: 305-308.

Vos, C.C. (1999): A frog's eye view on the landscape. Ph.D. Thesis. Wageningen, Netherlands, Institute for Forestry and Nature Research.

White, G., Garrot, R. (1990). Analysis of Wildlife RadioTracking Data. San Diego, Academic Press.

Received: November 29, 2004. Accepted: March 20, 2005. 